\title{
E-Proctored Model: Electronic Solution Architect for Exam Dereliction in Kenya
}

\author{
Edwin Omol ${ }^{1}$, Dr. Silvance Abeka ${ }^{2}$, Fred Wauyo ${ }^{2}$ \\ Department of Information and Communication Technology, Kisii University, Kisii, Kenya ${ }^{1}$ \\ School of Informatics and Innovative Systems, Jaramogi Oginga Odinga University of Science \& Technology, \\ Bondo, Kenya ${ }^{2}$
}

\begin{abstract}
The paper after reviewing various relevant literature proposes effective and efficient model to curb exam derelictions in pre-university exams in Kenya. Since all irregularities, including fraudulent results, have a devastating impact on public confidence in local public examinations, it is vital, and that over and above the application of detailed policy, the use of new technologies and information systems should be instrumental in minimizing and even preventing this menace from undermining the credibility of examination authorities. As academics, we strive to link assessment with the sorts of learning activities in which students and pupils engage and to employ a variety of assessment methods. ICT provides a link between learning, teaching and assessment. Examination computer systems should be designed in such a way that it not only supports the administration of examinations, but that it also becomes instrumental as a verification and validation system. This research therefore proposes e-Proctored in order to support current educational goals in pre-university exam test especially for primary schools in Kenya having been the beneficiaries of the governments' free laptop project. The study argues that developing and infusion of e-Proctored solution architecture by the Kenya National Examination Council (KNEC) remains the answer to curb examination malpractices in Kenyan primary schools especially acknowledging the efforts by the Government to introduce laptops in Kenya primary schools.
\end{abstract}

Keywords: Exam dereliction, e-Proctored Model, Exam Irregularity electronic Solution Architecture, e-Assessments.

\section{BACKGROUND}

The paper and pen (manual) method of writing examination, which has been in existence for decades, may not be appealing for use because of the problems usually experienced including examination venue capacity constraints, lack of comfort for examination candidates, delay in the release of results, examination malpractices, cost implication of printing examination materials and human error, Fagbola, (2013)

Examination dereliction is a serious problem in many educational systems in the world. It constitute one of the most disturbing problems facing the schools in Kenya today and they are constantly manifested and reported every year when examination results are released. According to Nyamoita, (2016), examination malpractice in Kenya has attained a frightening proportion given that it is not only sophisticated but also institutionalized. The value and functionality of any educational system lies in its ability to actualize the goals of education.

One of the aims of education and training is to instill the importance of integrity, honesty, and respect for others and hard work (Republic of Kenya, 2012). Examination derelictions work against this aim of education. It impact adversely on the anticipated standard of any educational system. They affect the integrity of the learning process, an individual's long-term behavior and the ability of academic institutions to achieve their stated objectives.
Ruwa (1997) describes examination derelictions as acts that involve noncompliance with an organization's rules and regulations. This involves manipulation, falsification, forgery or alteration of documents. Republic of Kenya (2005), views examination dereliction as an illegal or unethical behaviour by somebody in the process of testing an examinee's ability or knowledge by means of question. The World Bank Group (2002) define dereliction in public examinations as a deliberate act of wrongdoing contrary to official examination rules that is designed to place a candidate at an unfair advantage.

Saitoti, (2005) noted that examination derelictions have been reported in the Kenyan education system every year since 1995. Nyamoita, (2016), notes that with such occurrences, ethical standards for examinations are being compromised hence are becoming a cause for concern among stakeholders in the education sector globally.

Assessment accounts for a significant part of teachers' workload, especially in large student groups like standard eight children and form four students in Kenya, Saitoti, (2005). The use of e-assessment could help in addressing the enormous challenges experience by both Kenya government, teachers and the children undertaking the exams, Moreover with the demonstration of the Kenya government's willingness to incorporate and embrace 
Vol. 6, Issue 1, January 2017

computers in primary public schools its worthwhile to think of better ways of attacking this bull called exam Dereliction in the eye especially using God-gift technologies at our disposal.

\subsection{The e-exam in developing countries}

The great question facing modern Governments is: How does our education equip citizens to compete on the global arena? Tech-driven competitiveness requires an educational system that is strongly oriented towards producing citizens who are comfortable and productive in a hi-tech world. This is the major principle underlying the laptop project in schools within the African countries like Rwanda and Kenya. The intention is to prepare an entire generation of world-beating scholars, innovators, entrepreneurs and leaders who will take country like Kenya beyond Vision 2030 (Republic of Kenya, 2005). The aim is to transform these countries in a dramatic, positive and lasting way. It must lay a new platform for progress.

ICT integration in education means seamless incorporation of information and communication technologies to support and enhance the attainment of curriculum objectives, enhance the appropriate competencies including skills, knowledge, attitudes and values, and to manage education effectively and efficiently at all levels(Ross, Jeff, 2006) ). In order to transform education and address challenges of access, quality, relevance and equity faced by the education system, developing countries are adopting initiatives like Free Primary schools class one laptops project in Kenya by the Kenyan government to keep pace with global technological advancements.

\subsubsection{Bridge International Model}

In Kenya, Nigeria, and Uganda, Bridge International Academies (2008-present), a for-profit education company (referred to as 'Bridge' for short) can be applauded as the best example ever to have successfully championed the inclusion of ICT in their curriculum, they have developed an education model that leverages technology and scale to train and support under-served communities to deliver a pre-primary (nursery and kindergarten) and primary school education (Rangan, V. Kasturi, and Katharine Lee. 2010). The Bridge model—whether delivered through private or public schools - ensures a standard minimum level of quality through a comprehensive teacher support system and rigorous monitoring and evaluation. It trains its teachers in pupil-centered learning and provides each teacher with a tablet onto which it uploads daily teachers' guides, designed by a central academic team, with the materials and instructions to deliver lessons. Classes are measured quantitatively by tracking how far teachers progress through the daily lesson by daily syncing of teachers' tablets with the school leaders' smartphone via wireless hotspot, and qualitatively using roving academic support teams. This allows Bridge to iterate lessons and provide additional support in real-time. Tablets also monitor teacher attendance, triggering an alert to headquarters to send substitutes when teachers are absent (Rangan, V. Kasturi, and Katharine Lee. 2010.).

In conclusion, Bridge's use of technology enables it to collect vast amounts of data in real time that can be used to continuously drive improvements. In addition, teachers receive continuous training and support from professional development coaches on how best to utilize data and results from student assessments in their teaching (Herbling, David. 2015) and if such initiatives are adopted by developing countries' governments, the question "How does our education equip citizens to compete on the global arena?" shall have been answered. However, the Bridge's model failed to incorporate the greatest component of benchmarking the students' and teacher performance like computerizing examination process hence need for eProctored.

\section{2 e-Proctored:}

Electronic Proctored is a process involving the implementation of ICT for the recording, transmission, presentation and processing of Kenya Certificate of both Primary and secondary Education assessment material. Electronic assessment is presented as an alternative to traditional assessments where the assessment task is delivered and displayed on a computer screen via the internet (Jim Ridgway and Sean McCusker, 2016). A formal definition refers to e-assessment as the use of ICT for the presentation of assessment activity and the recording of responses (Bennett, RE, 2002). Thus, in order to provide an alignment between the teaching, learning and assessment processes, it is essential to employ the use of ICT in assessment (Adams, C and Hudson, G, 2004). Additionally, Chapman, OL and Fiore, MA (2001) suggests that due to paradigm shift in educational technology, it may become unfair to train students on computers and then use pens for assessments. Adopting electronic assessments in an education environment embodies enormous benefits such as, automatic marking, immediate feedback to students, opportunities for lifelong learning and improved access for disabilities or geographically dispersed students. The three types of assessment which may be employed for assessing include: formative, summative and diagnostic assessment.

1.2.1 Formative Assessment: Early work in formative assessment is attributed to leading theorists in education (Herbling, David. 2015) .Formative implies a process or product which is capable of developing or shaping. Formative assessment is influenced by the need to provide information to students, in a manner that will contribute to the use of their acquired skills. Thus, the aim of formative assessment is to help students' learn something (Gathuri, 2014).As described by Herbling, David. (2015) traditional formative assessment has commonly taken the form of: i. Non-assessable activities and feedback in study materials

ii. Self-assessment quizzes and tests that help students monitor their own progress 
iii. Feedback from assignments, or from peers, colleagues or mentors

iv. Dialogue with teachers, tutors and other students

v. Non-assessable tests that prepare students for formal examinations Formative assessment takes place while a class is ongoing and it continuously monitors student progress rather than at the endpoint. This type of assessment provides a short term feedback loop which offers insight into the student's strengths and their conceptual errors (Gathuri, 2014) .Thus, the students are presented with opportunities to improve. In another view, Nyamoita, (2016), describes formative assessment as the means to identify the "gap" between a student's current understanding and the desired goal. Jim Ridgway and Sean McCusker, (2016) suggest that different students will have different "gaps" and the lecturers should design strategies to identify and close these gaps.

1.2.2 Summative Assessment: Summative assessments are administered to record or report an estimate of the student's achievements (Fagbola, 2013).Summative assessments are also called high-stakes assessments when used for promotion, placement, certification, and accountability (Chapman, OL and Fiore, MA 2001).Thus, reliability is central to summative assessments; since the results may have an enormous impact on students' academic future. For summative purposes, achievement is generally summarized in terms of grades, which aids in the comparison and classification between students. However, summative assessment should be viewed in terms of accountability rather than as a means of classifying students. Therefore, when summative assessments are focused on grading or classification, students are likely to do their best to obtain good marks and look competent in comparison with their peers (Black, $\mathrm{P}$ and Wiliam, D 2002).In conclusion, the goal of a summative assessment is to provide overall information on the amount and quality of the student learning.

1.2.3 Diagnostic Assessment: Diagnostic assessment has been associated as a testing carried out by educational psychologists for students with learning difficulties. However, in modern education it is used to identify a student's strengths and weakness or prior knowledge and skills in relation to a course program (Adams, C and Hudson, G 2004).Diagnostic assessment sits between summative and formative assessments and it can be used to diagnose a student's ability at the beginning of a course (Ross, Jeff , 2006).In formative assessment, an initial diagnosis aids in making decisions about a student's skills whilst as a summative test it serves as a basis for making a decision about a student's suitability for entry to a course (Shepherd, 2010).Traditionally, diagnostic assessment may take the form of a one-to-one session with a career counsellor; however, in an online mode computerized diagnostic tools replace the physical advisor (Ross, Jeff 2006). The diagnosis may present the lecturer with an overview of the students' ability, which may influence their teaching strategies. For example, in a work environment, a job applicant may be required to undergo a diagnostic test in order to determine the individual's competency for a job and the extra skills that may be needed. Hence, it is futile for a student to cheat during diagnostic assessments; since the test is aimed at identifying strengths and weakness to aid intellectual growth. Thus, the students' who cheat during a diagnostic assessment may pass the test, feigning competency in the subject area. However, due to the lack of appropriate knowledge, the fraudulent students may have to continue cheating till the end of the course (Gathuri, 2014). Therefore, it is important to ensure adequate security during diagnostic assessments to avoid security breaches during high-stake assessments.

\section{3 e-Exam in developed countries}

In Australia, the Government is committed to a Digital Education Revolution with focus on students in Years 912 who shortly percolate into universities (Roan, M, 2003). Government is concerned about lethargic ICTbased transformation in education: "while ICT has fundamentally reshaped whole industries, revolutionised production processes and generated massive improvements in productivity in the workplaces, the education systems are slower in adapting" (Roan, M, 2003). This makes the adoption of ICT in education a problem of national significance, and therefore understanding the use of ICT in assessment is vital. This has been recognized overseas with an annual conference on eAssessment in the UK over the past 13 years (Ross, 2006) which involves many accreditation agencies.

Research into school student acceptance of eAssessment is being conducted by the National Foundation for Educational Research (Burge, Foster \& Lewis, 2006). In addition, there are emerging regulatory principles for eAssessment in school education (e.g. Qualifications and Curriculum Authority, UK, 2007).The UK government is committed to a bold e-assessment strategy whose Components include: ICT support for current paper-based assessment systems; some online, on-demand testing; and the development of radical, ICT-set and assessed tests of ICT capability. Some good progress has been made with these developments.

\subsubsection{Pearson VUE Model}

In 1994; Clarke Porter, Steve Nordberg and Kirk Lundeen, pioneers in the electronic testing industry, set out to create a world-class training services company that would help the IT industry better serve its learners. Virtual University Enterprises (VUE) launches to connect people with authorized certification training, In 2014 Provusion was launched, the training and learning marketplace developed exclusively for Pearson VUE Authorized Test Centers; Launch of remote proctored delivery, Pearson VUE launches Acclaim, a new enterprise badging solution that offers a new way to issue, verify and share digital credentials. Pearson VUE provides licensure and certification exams for Microsoft, Cisco, compTIA, 
Oracle, HP, GMAC, NCLEX and others (Pearson VUE, 2016).

Pearson VUE model applies Non-Proctored Tests which are unsupervised. Many times they are online assessments that a candidate takes from home. Remote assessments have several advantages in that they are easy to administer, candidates can take them at their convenience, and a proctor is not needed. However, the risk with some non-proctored assessments is there is always a chance that the candidate solicited outside help. Because of this possibility, we therefore highly recommend Proctored computer-based Tests to Kenyan exam situation where someone is present while the candidate is taking the assessment (Jen_Garrow, 2012). Proctored tests can be administered on a computer or using paper and pencil. Depending on the type of test, the proctor may or may not have to be certified. Proctored assessments are the optimal administration format. You know for certain that the responses are to be given without input from other people or the use of supplemental tools (calculators, text books, etc.). The environment can also be controlled hence eliminating the risk of distraction.

\subsection{The proposed e-Proctored Model}

The Kenya Certificate of Primary Education and Kenya Certificate of Secondary Education examinations in Kenya have become a do-or-die situation. Unless you pass Kenya Certificate of Primary Education, you will not join the best secondary schools in the country, or you may easily be part of the 250,000 candidates that may not proceed to any secondary school.

Unless you pass Kenya Certificate of Secondary Education, you may not join the University, and upon this transition, your future and fate will be determined. Passing or failing examinations in Kenya is like missing the password to successful living. At least this is how Kenyans perceive it, and due to this the Kenyan parents and students strive through thick and thin just to better their final results despite the Kenyan law being tough on examinations irregularities; provide an examination paper to a candidate before the examination begins, and we either imprison you for 10 years or fine you up to Sh2 million. Disclose the contents of an examination paper, and we imprison you for five years or fine you up to one million shillings. These are the stringent provisions of the Kenya National Examination Council's (KNEC) Act, which became law on the October 19, 2012.

Despite this law, leakage of examinations has been on rapid increase. This raises a legitimate question; can criminalizing cheating, and guarding the examinations even more, curb examinations irregularities? At least from our Kenyan experience, this seems inadequate. So, why do Kenya National Examination Council's (KNEC) officers, teachers and parents collude to cause examinations irregularities, even when they know that they are breaking the law, and even causing a greater generational problem, passing on dishonesty and law-breaking attitudes to our children? The answer to this question is one - the stakes are just too high and an alternatives like introduction of eKCPE must be embraced .This paper therefore illustrates the contribution of ICT to assessment in developing countries especially Kenya. E-assessment can be justified in a number of ways. It can help avoid the meltdown of current paper-based systems; it can assess valuable life skills; it can be better improved. The proposed model have the following components:

1. Enrollment Interface: Comprising the registration and login page as the default page of the system. This is where all the users are validated and redirected to their respective user interfaces, an id number and password field are provided as well as check boxes for every user. The Kenya National Examination Commission staff is a combination of both the teacher, lecturer and invigilators which the system should automatically detect the role of the user using their id number.

2. The Authentication Mechanisms: The model propose comparing the credentials provided to those on file in a database of authorized users' information on a local operating system or within an authentication server. If the credentials match, the process is completed and the user is granted authorization for access with options range from creating a new user, deleting existing users, viewing and editing existing users, viewing examination questions, creating/deleting new courses, viewing and editing courses, setting examination timetable, viewing results, changing password and viewing information about the application based on the role played by the user.

3. The learning resource: This' where the student or pupils take examination. It allows student or pupils to take examination, examination questions are randomly gotten from the question table in the database and displayed to the student. The student selects a radio button that corresponds to the appropriate answer. At the end of the exam, result is displayed to the student and stored in the KNEC database.

4. The Result: The result page is presented in figure 1.1. This page enables the student to view exam result after they have taken the exam, it displays the students ID number, the course code of the exam taken, the date of the exam, and the marks obtained by the student.

The paper recommends a web based implementation of this model, designed and developed using Java and MySQL to address all these challenges. However it should also take note of the social factors such as infrastructural support, electricity supply, and skilled ICT workers and so on for a successful implementation. The model is limited to multiple choice based question and should be developed under a severe resource constraint. Thus, there is scope for undergoing more studies that would take into account theory based questions. 


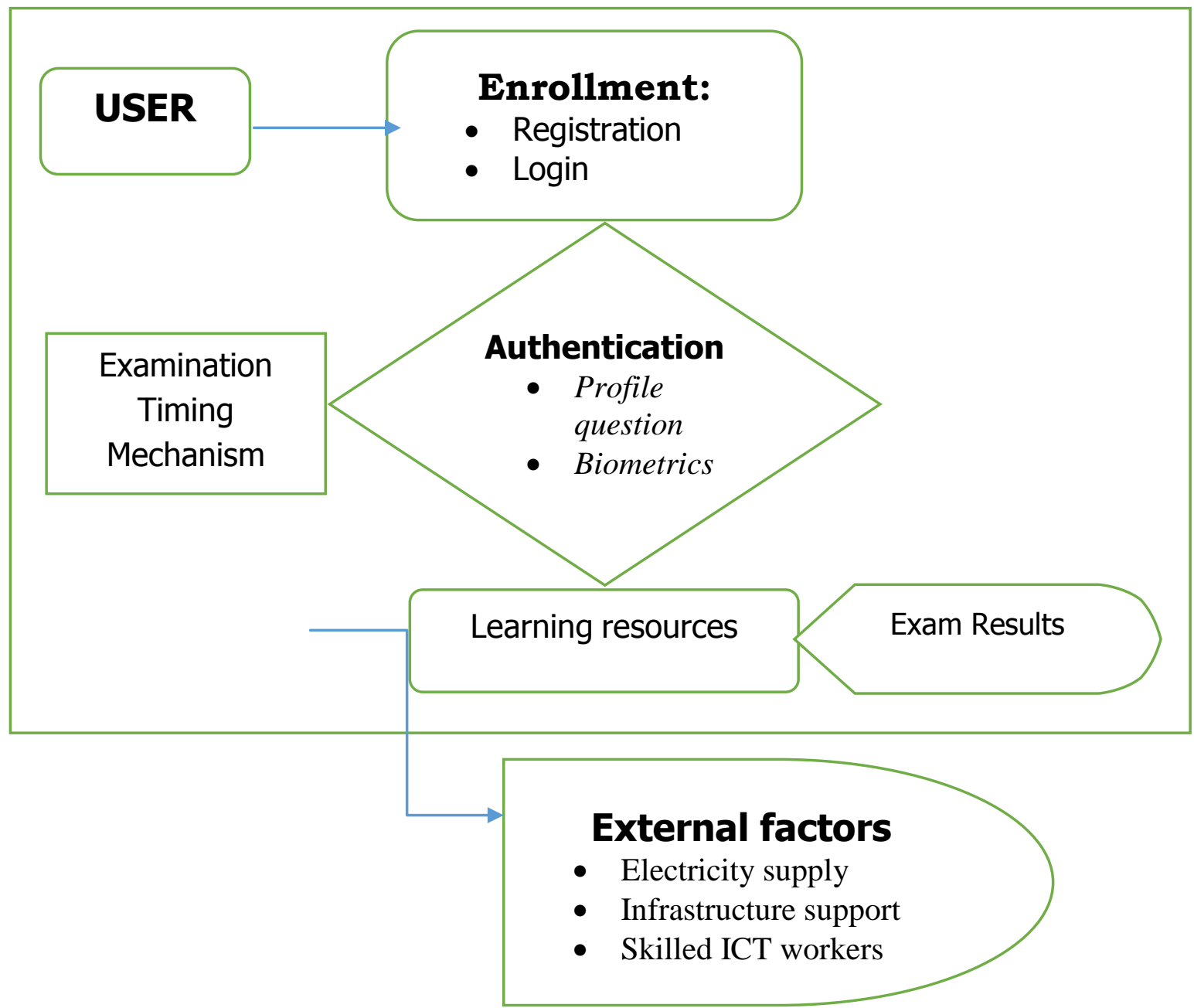

Fig 1.1 Proposed e-Proctored Model

\section{CONCLUSION}

The use of new technologies in the management and administration of examinations in developed countries has been going on for a long time. The employment of such new technologies in examinations management and administration is part and parcel of the strides achieved in the field of science and technology in those countries. In developing countries like Kenya such technologies have been similarly adopted in varying degrees in various stages of Examinations administration especially in Universities. The aim of employing these new technologies is to streamline the procedures and processes of examinations management and administration. In this paper, the authors have evaluated the existing examination process in Kenya and proposed a web-based examination system model for adoption in Kenya pre-university institutions more so primary schools. The current challenges facing the existing examination process in this study include high cost of printing papers, manpower examination malpractice, and human errors during marking, omission of students result, inadequate examination venues and invigilators. An electronic based examination system designed and developed using Java and MySQL is therefore the answer of all these challenges. However it should be also noted that the implementation of this model requires other social factors such as infrastructural support, electricity supply, and skilled ICT workers and so on for a successful implementation. The proposed model is limited to multiple choice based question and is to be developed under a severe resource constraint. Thus, there is scope for undergoing more studies that would take into account theory based questions.

\section{REFERENCES}

[1] Adams, C and Hudson, G (2004). AQA and DRS electronic mark capture, presented at the QCA E-assessment Summit, 24 April Aim Online P-10 Supplement (2003). Supplement to the VCAA Bulletin No 6 September 2003. AIM Online: www.aimonline.vic.edu.au

[2] Bennett, RE (2002). Inexorable and inevitable: the continuing story of technology and assessment. Journal of Technology, Learning, and Assessment, i(i). Available from www.jtla.org

[3] Black, P and Wiliam, D (2002). Assessment for Learning: Beyond the Black Box (2002). www.assessmentreform-group.org.uk/ publications.html

[4] Chapman, OL and Fiore, MA (2001). Calibrated peer review: a writing and critical thinking instructional tool. The White Paper: a Description of CPR. http://cpr.molsci.ucla.edu/ 
[5] Fagbola, T. M. et al, (2013). Computer-Based Test (Cbt) System For University Academic Enterprise Examination. International Journal of Scientific \& Technology Research Volume 2, ISSUE 8, AUGUST 2013.

[6] Jen_Garrow on Friday, December 7, 2012 - 8:00am retrieved from: http://blog.wonderlic.com/proctored-vs-non-proctored-testingwhat-to-consider

[7] Jim Ridgway and Sean McCusker, (2016). Literature Review of Eassessment, School of Education, University of Durham Daniel Pead, School of Education, University of Nottingham, retrieved from www.futurelab.org.uk/research.

[8] Gathuri,J. W et al, (2014). Impersonation Challenges Associated With E-Assessment of University Students. Journal of Information Engineering and Applications

[9] Herbling, David. 2015. "Ministry Stops Expansion of Low-Cost Schools," Business Africa Daily. Accessed April 7, 2016 from http://www.businessdailyafrica.com/Kenya-stops-expansion-ofBill-Gates-backed-chain-ofschools/-/539546/2883462/-/81t0tq//index.html.

[10] Nyamoita, G. B. et al (2016), Effectiveness of Kenya National Examinations Council Measures in Curbing National Examination Malpractices in Public Secondary Schools in Kisii County, IJSRM volume 4 issue 2 Feb 2016 [www.ijsrm.in]

[11] Republic of Kenya (2005). Sessional Paper No. 1; Policy Framework for Education, Training and Research. Nairobi: Government Printer.

[12] Republic of Kenya (2012). The draft Kenya national examinations council bill. Retrieved 15 may 2012.Nairobi: Government Printer

[13] Ruwa, M. (1997). Examination malpractices: A case study of the University of Maiduguri. Journal of Educational Studies, 5(1), 26. http://www.naere.org/article. Retrieved 15 may 2012.

[14] Rangan, V. Kasturi, and Katharine Lee. 2010. "Bridge International Academies: A School in a Box." Harvard Business School Case Study. Retrieved from: http://www.bridgeinternationalacademies. com/approach/model/

[15] Ross, Jeff (2006). The e-Assessment question 2007: 'Using ICT to measure skills, understanding and knowledge'. London, England. Retrieved 10th January 2007, from http://www.eassessment question.co.uk/ on.

[16] Roan, M (2003). Computerized assessment: changes in marking UK examinations - are we ready yet? Paper presented to the 29th Annual Conference of the International Association for Educational Assessment. www.aqa.org.uk/ support/iaea/papers/roan.pdf

[17] Shepherd, J. (2010). Exams: Changing habits may spell end for pen-and-paper tests. The Guardian Retrieved 4 September 2010, from http://www.guardian.co.uk/education/2010/aug/18/examskeyboard-answers-ofqual Saitoti, G. (2005). Irregularities during the 2004 KCSE examination. Press statement.

[18] Retrieved from: http//www.education.go.ke/keyspeeches.htm souv, on examination malpractices in Kenya.

[19] Pearson VUE, (2016) retrieved from: https://home.pearsonvue.com/ About-Pearson-VUE/Company-information/Company-history.aspx

\section{BIOGRAPHIES}

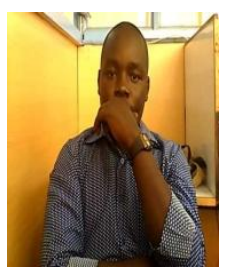

Edwin Omol holds Masters of Science in Information Systems from Kisii University, Bachelors of Science and Diploma in Information Technology from KCA University and; CISCO-ITE $(\mathrm{A}+)$ and CCNA certified. He has been involved in a number of research projects of ICTs and development, including eMoney project, E-learning systems, Technology Acceptance, Mobile Technology, Management Information Systems, Routing and Switching, Web- Design, E- Commerce and E-exam management in Kenya. Besides, he has published widely in journals and conference proceedings in Information technology and ICTs for development.
Moreover he's a diligent and hardworking young man who is self-motivated.

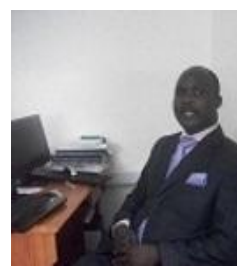

Dr. Silvance Abeka is currently a Senior Researcher and dean, School of Informatics and Innovative Systems, Jaramogi Oginga Odinga University of Science \& Technology and previously dean- Faculty of Applied Science and Technology and also a senior Lecturer at Kampala International University- Dar es Salaam Collage in the Department of Computer Studies. He holds $\mathrm{PhD}$ in Management Information System (MIS) and Master's degree in Business Administration (Information Technology), from Kampala International University Dar es Salaam Collage and ; Masters of Science in Computer Science from University of Dar es Salaam. His research interests include IT innovation adoption, open source software study, and IT offshoring, Management Information Systems, Principles of Statistics, Web- Design and E- Commerce.

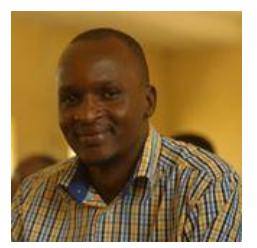

Fred Wauyo holds MBA. In Information Technology from Kampala International University, BSc in Information Technology from Islamic University in Uganda. And Diploma in Computer and Information Technology from Islamic University in Uganda and CCNA and Certified Cisco Instructor from Makerere University Uganda, Oracle Certified Associate. $\mathrm{He}$ has done research projects of ICTs and Intelligence Technologies, including, E-learning systems, writing Mob Applications, IT innovation and absorptive capacities of users, open Source Software study, Management Information Systems, Routing and Switching, Web Content developments of Dynamic Websites, Information Technology Administration through Linux and Ubuntu. Programming Skills in Java, $\mathrm{C} / \mathrm{C}++, \mathrm{PhP}$ and Pearl and self- driven. 